\title{
Cytotoxic immune cell-based immunotherapy for hepatocellular carcinoma
}

\author{
Jing $\mathrm{Li}^{1}$, Longxiang $\mathrm{Tao}^{2}$, Xuefu Wang ${ }^{3}$ \\ 'School of Life Sciences, Anhui Medical University, Hefei 230032, Anhui, China. \\ ${ }^{2}$ Department of Radiology, The First Affiliated Hospital of Anhui Medical University, Hefei 230022, Anhui, China. \\ ${ }^{3}$ School of Pharmacy, Anhui Medical University, Hefei 230032, Anhui, China.
}

Correspondence to: Xuefu Wang, PhD, School of Pharmacy, Anhui Medical University, \#81, Meishan Road, Hefei 230022, Anhui, China.

E-mail: wangxuefu@ahmu.edu.cn

How to cite this article: Li J, Tao L, Wang X. Cytotoxic immune cell-based immunotherapy for hepatocellular carcinoma. Hepatoma Res 2020;6:15. http://dx.doi.org/10.20517/2394-5079.2019.34

Received: 17 Nov 2019 First Decision: 24 Feb 2020 Revised: 16 Mar 2020 Accepted: 24 Mar 2020 Published: 10 Apr 2020

Science Editors: Jia Fan, Ying-Hong Shi Copy Editor: Jing-Wen Zhang Production Editor: Tian Zhang

\begin{abstract}
Hepatocellular carcinoma (HCC) is one of the most common solid tumors with poor clinical prognosis. Novel therapeutic regimens are urgently required for patients with advanced HCC. Both pre-clinical and clinical studies suggest immunotherapy as an attractive alternative for advanced HCC treatment. Natural killer (NK) cells and $\mathrm{CD} 8^{+} \mathrm{T}$ cells are the most important cytotoxic immune cells involved in cancer treatment and elimination. Reinvigorating the anticancer activity of $\mathrm{NK}$ and $\mathrm{CD} 8^{+} \mathrm{T}$ cells is the fundamental guarantee for the success of immunotherapy in advanced HCC treatment. Therefore, in this review, we aim to summarize the characteristics and roles of NK and $\mathrm{CD} 8^{+} \mathrm{T}$ cells in HCC development, describe the frontiers of immunotherapy for advanced $\mathrm{HCC}$ based on immune checkpoint inhibitors and adoptive cell transfer, and discuss their limitations and scope for future improvement.
\end{abstract}

Keywords: Hepatocellular carcinoma, immunotherapy, natural killer cells, CD $8^{+} \mathrm{T}$ cells

\section{INTRODUCTION}

Although hepatocellular carcinoma (HCC) is only the fifth-most common cancer worldwide, it ranks second in cancer-related mortality ${ }^{[1]}$. Local regional therapies such as surgical resection, cryoablation, radiofrequency ablation, transarterial chemoembolization, and liver transplantation are effective only for patients with earlystage $\mathrm{HCC}^{[2]}$. Multi-targeted tyrosine kinase inhibitors (TKIs) provide options for systemic treatment of

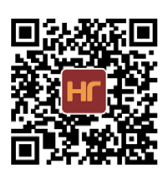


patients with advanced HCC. The first-line agent sorafenib modestly extends the survival in advanced HCC by about 3 months ${ }^{[3]}$. Lenvatinib has been approved for HCC treatment based on the results of a randomized phase III trial, in that lenvatinib is non-inferior to sorafenib in overall survival assessment in patients with advanced HCC, with similar safety and tolerability profiles as sorafenib ${ }^{[4]}$. Regorafenib and cabozantinib have been approved as second-line options for patients with progressive HCC despite on-going sorafenib treatment, in that they improve overall survival in such patients ${ }^{[5-7]}$. Nonetheless, the survival benefit from the TKIs is limited and unexpected. Therefore, novel clinical therapies are urgently required for treatment of early-stage and advanced HCC. Recently, immunotherapy with immune checkpoint blockade and adoptive immune cell transfer has been clinically tested in various types of cancers, which provides a novel therapeutic strategy for difficult-to-treat HCC cases. The present review aims to summarize the characteristics and roles of natural killer (NK) cells and $\mathrm{CD}^{+} \mathrm{T}$ cells during HCC development, describe the frontiers of immunotherapy for advanced HCC based on immune checkpoint inhibitors (ICIs) and adoptive cell transfer $(\mathrm{ACT})$, and discuss their limitations and scope for future improvement.

\section{NK CELLS AND CD8 ${ }^{+}$T CELLS IN HCC}

The liver contains diverse types of immune cells such as T cells, NK cells, B cells, NKT, and Kupffer cells ${ }^{[8,9]}$. However, the liver is a tolerogenic immune organ in the physiological state, in that the liver remains tolerant to stimuli from the hepatic artery and portal vein, such as bacterial products, environmental toxins, and food antigens, to avoid tissue damage ${ }^{[10,11]}$. This immune-tolerant microenvironment of the liver contributes to the immunoescape of $\mathrm{HCC}^{[12]}$. Studies have extensively discussed the properties and contribution of immunosuppressive cells during HCC progression ${ }^{[13]}$. However, to our best knowledge, the characteristics and contribution of the two most important anticancer immune cells in the liver - NK cells and $\mathrm{CD}^{+} \mathrm{T}$ cells - have not been well-documented.

\section{NK cells in HCC}

Innate lymphoid cells (ILCs) function as the first line of immune defense against infections and cancers. Paralleling with T cell subsets, ILCs comprise NK cells, ILC1, ILC2, and ILC3, amongst which the NK and ILC1 cells are abundant in the liver ${ }^{[14,15]}$. Unlike helper ILC subsets, NK cells are classified as a cytotoxic ILC subset because of their direct killing of cancer cells and infected cells via cytotoxicity and cytokine secretion ${ }^{[16]}$. NK cells express activating receptors such as CD16, NKp30, NKp44, NKp46, NKp80, NKG2D, CD244, CD226; cytokine receptors such as IL-2R, IL-28R, IL-12R, IFNR, IL-15R, IL-18R, IL-1R8, IL-10R, and TGFR; and inhibitory receptors such as NKG2A, KLRG1, KIRs, TIGIT, TIM3, Siglecs, PD-1, LAG3, A2AR, LAIRs, and ILTs ${ }^{[17,18]}$. The activation of NK cells is determined by the net value of activating signal strength determined by the competition between activating and inhibitory receptors ${ }^{[17,19]}$. The abundance and activity of NK cells are modulated by multiple signals within the tumor microenvironment, which significantly influence cancer development. Compared with healthy controls, HCC patients have a dramatic reduction of tumor-infiltrating NK cells; their abundance in HCC tissues is positively correlated with patient survival $^{[20]}$. NK cells in the HCC tissues of patients with advanced HCC show dysfunctional or exhausted state $^{[20]}$, suggesting that NK-cell exhaustion contributes to HCC progression. The regulators for NK cell exhaustion have been extensively investigated. For example, the up-regulation of inhibitory receptors on NK cells leads to NK-cell exhaustion and predicts poor prognosis in HCC patients ${ }^{[21]}$. TGF- $\beta$ and IL-10 promoted NK-cell exhaustion in $\mathrm{HCC}^{[22,23]}$. Hypoxia-induced mitochondrial fragmentation limits NKcell anticancer activity ${ }^{[24]}$. Additionally, immunosuppressive cells such as myeloid-derived suppressor cells, monocyte/macrophage, and HCC-associated fibroblasts in intratumor tissues of HCC contribute to NKcell exhaustion ${ }^{[25-27]}$. The plasticity of NK cell activity provides the foundation of NK-cell-based cancer immunotherapy. Immunotherapeutic drugs triggering NK-cell activation are being developed and assessed in pre-clinical and clinical trials. Nevertheless, it is still crucial to decipher the mechanisms by which NK cells undergo exhaustion in patients with advanced HCC, in order to offer more patient benefits in terms of effective reinvigoration of NK-cell anticancer activity and precision therapy in HCC. 
NK cells have been reported to account for $20 \%-40 \%$ of human hepatic lymphocytes and $10 \%-20 \%$ of murine hepatic lymphocytes, more than half of which bona fide comprise ILC1 or liver-resident NK cells ${ }^{[28]}$. The observations from the parabiosis model show that the liver contains conventional NK cells and liver-resident $\mathrm{NK}$ cells ${ }^{[2]}$, further supported by the findings that hepatic irradiation could persistently eliminate liverresident NK cells ${ }^{[30]}$. Early evidence has shown that liver-resident NK cells expressed higher levels of CD160, CD69, CD44, CXCR3, CXCR6, TRAIL, FasL, GM-CSF, and TNF- $\alpha^{[29]}$. CXCR6 is required for the retention of liver-resident NK cells within the liver ${ }^{[31]}$. $\mathrm{CD}^{+} \mathrm{T}$ cells promote liver-resident NK cell maturation through the CD70-CD27 axis ${ }^{[32]}$. Liver-derived TGF- $\beta$ maintains the property of liver-resident NK cells ${ }^{[33]}$. Functionally, liver-resident NK cells were originally found to mediate skin-contact inflammation ${ }^{[29]}$. Zhou et al ${ }^{[34]}$ reported that liver-resident NK cells inhibited T cell antiviral activity via PD-L1 during viral infection. Additionally, liver-resident NK cells can suppress autoimmune cholangitis by limiting the expansion of $\mathrm{CD}^{+} \mathrm{T}$ cells ${ }^{[35]}$. These findings suggest that liver-resident NK cells play versatile roles in liver diseases. Human liver-resident NK cells are $\mathrm{CD} 56{ }^{\text {bright }}$ Eomes ${ }^{\text {hi }}$ Tbet $^{\text {lo }}$ Hobit $^{+}$TIGIT $^{+} \mathrm{CD} 9^{+} \mathrm{CXCR}^{+}{ }^{+} \mathrm{CD} 49 \mathrm{e}$; express higher levels of NKG2D, NKp46, TRAIL, and FasL; and possess cytotoxicity against HCC cells ${ }^{[36]}$. However, liver-resident NK cells within the HCC tissue down-regulate $\mathrm{NKG}_{2} \mathrm{D}^{[37]}$. Moreover, liver-resident NK cells express more types of inhibitory receptors such as PD-1, CD96, and TIGIT ${ }^{[38]}$. Therefore, liver-resident NK cells undergo exhaustion during HCC progression. Fortunately, IL-15 could recover HCC-induced liver-resident NK-cell dysfunction $^{[37]}$. In addition, the mTOR inhibitor - everolimus - enhances their anticancer activity through upregulation of TRAIL ${ }^{[39]}$. Thus, liver-resident NK cells have the potential for application in HCC therapy, although the complete underlying mechanism of liver-resident NK cells' exhaustion remains unclear.

\section{$\mathrm{CD}^{+} \mathrm{T}$ cells in HCC}

The abundance of tumor-infiltrating $\mathrm{CD} 8^{+} \mathrm{T}$ cells and the frequency of $\mathrm{IFN}-\gamma^{+} \mathrm{CD} 8^{+} \mathrm{T}$ cells were associated with improved survival of HCC patients ${ }^{[40,41]}$. $\mathrm{CD}^{+} \mathrm{T}$ cells were enriched in early-stage HCC, but progressively reduced with tumor progression, accompanied with increased expression of checkpoints on tumor-infiltrating $\mathrm{CD}^{+}{ }^{+} \mathrm{T}_{\text {cells }}{ }^{[42]}$. Therefore, $\mathrm{CD}^{+}{ }^{+} \mathrm{T}$ cells in HCC tissues progressively underwent functional compromise during cancer progression, characterized by high levels of immune checkpoints, low effector cytokines, and impaired cytotoxicity and proliferation. In detail, however, $\mathrm{CD}^{+}{ }^{\mathrm{T}}$ cells in HCC tissues expressed different PD- 1 levels and displayed different anticancer capacity ${ }^{[43]}$. Among PD- ${ }^{\text {high }} \mathrm{CD}^{+}$ $\mathrm{T}$ cells, $4-1 \mathrm{BB}^{+} \mathrm{PD}-1^{\text {high }} \mathrm{CD}^{+} \mathrm{T}$ cells displayed stronger anticancer activity and proliferative potential ${ }^{[44]}$. In recent times, several studies have reported that $\mathrm{TCF}-1^{+} \mathrm{PD}-1^{+} \mathrm{T}$ cells sustained the stemness and response to immune checkpoint blockade in certain types of cancers ${ }^{[45,46]}$. Therefore, the identification of functional tumor-infiltrating $\mathrm{CD}^{+} \mathrm{T}$ cells for immunotherapy will likely benefit clinical outcomes and promote precision medicine for HCC patients.

The systemic, local, cellular, and molecular mechanisms of T-cell exhaustion in HCC have been extensively investigated. The hepatic inflammatory microenvironment had been confirmed to be critical for HCC development ${ }^{[47]}$. Lim et al. ${ }^{[48]}$ found that HBV-related HCC microenvironment displayed more immunosuppression than non-viral-related HCC microenvironment, indicating increased difficulty in the immunotherapy of HBV-related HCC. Hepatoma cells, LSECs, suppressive immune cells, inhibitory receptors, and cytokines have been found to trigger tumor-infiltrating $\mathrm{CD}^{+}{ }^{+} \mathrm{T}$-cell exhaustion ${ }^{[49]}$. For instance, myeloid-derived suppressor cells and T regulatory cells in HCC tissues had been found to impair T-cell functionality ${ }^{[50]}$. The inhibitory cytokine - IL-35 - dampened $\mathrm{CD}^{+}{ }^{+}$T cells activity in HCC patients ${ }^{[51]}$. 14-3-3 , a suppressor of apoptosis, is highly expressed in HCC and promotes epithelial-mesenchymal transition of HCC cells ${ }^{[52]}$. Wang et al. ${ }^{[53]}$ reported that $14-3-3 \zeta$ delivered by HCC-derived exosomes contributed to impaired anticancer activity of $\mathrm{CD}^{+} \mathrm{T}$ cells. The thymocyte selection-associated high mobility group box (TOX) transcription factor belongs to an evolutionarily conserved DNA-binding protein family and regulates the development of $\mathrm{T}$ cells ${ }^{[54]}$. Recently, several studies have confirmed that TOX was critical for $\mathrm{CD}^{+}{ }^{+}$cell exhaustion ${ }^{[55,56]}$. Moreover, it was found that TOX could promote $\mathrm{CD}^{+} \mathrm{T}$-cell exhaustion in 
HCC tissues by restraining PD-1 degradation ${ }^{[57]}$. The complicated immunosuppressive microenvironment in HCC tissues severely impairs the efficacy of immunotherapy. Therefore, the mechanisms of $\mathrm{CD}^{+} \mathrm{T}$-cell exhaustion in HCC needs to be further elucidated.

\section{CYTOTOXIC IMMUNE CELL-BASED IMMUNOTHERAPY OF HCC}

The increased understanding of $\mathrm{CD}^{+}{ }^{+} \mathrm{T}$ cells and NK cells promotes the development of effective immunotherapy. These two immune cell populations follow many similar patterns and/or complementary patterns to eliminate cancer cells. Moreover, their activities are regulated by common immune checkpoints. Here, we discuss the application and outcomes of cytotoxic cell-based ICIs and ACT in HCC treatment.

\section{Immune checkpoint inhibitors}

ICIs have displayed impressive efficacy in treating a variety of cancers. An increasing number of studies are being conducted on novel immune checkpoints and their inhibitors. Additionally, studies on ICIbased immunotherapy for advanced HCC treatment are also increasing, with some showing encouraging therapeutic effects.

\section{Anti-PD-1 antibody and anti-PDL1 antibodies}

$\mathrm{PD}-1$ is mainly expressed on $\mathrm{CD}^{+}{ }^{+} \mathrm{T}$ cells, whose binding with $\mathrm{PD}-\mathrm{L} 1 / \mathrm{PD}-\mathrm{L} 2$ induces $\mathrm{CD} 8^{+} \mathrm{T}-\mathrm{cell}$ exhaustion ${ }^{[58]}$. T cells from HCC tissues express high levels of PD- ${ }^{[59,60]}$. Interestingly, PD- ${ }^{\text {high }}$ B cells in HCC tissues suppressed $\mathrm{CD} 8^{+} \mathrm{T}$-cell anticancer immunity by secreting $\mathrm{IL}-10^{[61]}$. Moreover, PD- ${ }^{+}$dendritic cells (DCs) in HCC tissues also suppressed $\mathrm{CD}^{+}$T-cell anticancer immunity ${ }^{[62]}$. In addition, PD-1 ligands are associated with aggressiveness and recurrence of $\mathrm{HCC}^{[63,64]}$. Wu et al ${ }^{[65]}$ reported that PD-L1 on Kupffer cell blocks $\mathrm{CD}_{8}{ }^{+} \mathrm{T}$-cell anti-HCC activity. Besides, hepatoma cell-expressed PD-L1 induces apoptosis of CD8 ${ }^{+}$ $\mathrm{T}$ cells and promotes HCC recurrence ${ }^{[66]}$. Additionally, PD-L1-expressing monocytes induce polarization of Th22 cells through PD-1 in HCC tissues ${ }^{[67]}$. PD-L1 on intratumoral hepatic stellate cells or peritumoral neutrophils also contributes to the impairment of T cell-mediated anti-HCC immunity ${ }^{[68,69]}$. These findings indicate that blockade of PD-1/PD-L might be promising immunotherapy for HCC. Nivolumab and pembrolizumab gained approval for treatment of advanced HCC based on encouraging results from phase I/II studies in advanced HCC patients with objective response rates of $17 \%-20 \%{ }^{[70,71]}$. However, results from two phase III clinical studies did not reveal statistically significant improvement in survival benefit ${ }^{[72,73]}$. There are several ongoing trials with monoclonal antibodies against PD-1, such as nivolumab, pembrolizumab, tislelizumab, and camrelizumab, in HCC patients, either as monotherapy or in combination with other treatments. A phase-I/II study reported that the combination of atezolizumab and bevacizumab resulted in a $62 \%$ response rate in advanced HCC patients ${ }^{[74]}$. The breakthrough therapy of atezolizumab in combination with bevacizumab is recently approved as a first-line treatment for patients with advanced or metastatic HCC. Moreover, a randomized phase III study demonstrated superior overall survival and progression-free survival compared to sorafenib in the first-line treatment of advanced $\mathrm{HCC}^{[75]}$. In addition, another antiangiogenic drug ramucirumab has been approved as a second-line therapy for advanced HCC following first-line therapy with sorafenib ${ }^{[76]}$. The clinical efficacy from the combination of anti-PD-L1 with antiangiogenic agents encourages researchers to extensively develop novel combination strategies to improve the clinical efficacy of HCC treatment.

\section{Anti-CTLA-4 antibody}

CTLA-4 is expressed on Treg cells and activated T cells and inhibits T-cell activation by competing for CD80/CD86 with CD28 ${ }^{[77]}$. Liu et al..$^{[78]}$ found that CTLA-4 polymorphism may have negative effects on HCC. CTLA $-4^{+}$Treg cells impair T cell-mediated anti-HCC immunity ${ }^{[50]}$. HCC-derived Treg cells limit DCs function by CTLA- ${ }^{[79]}$. Furthermore, CTLA- $4^{+}$DCs suppress $\mathrm{T}$ cell-mediated anti-HCC immunity by IL-10 and IDO ${ }^{[80]}$. Fortunately, CTLA-4 blockade with glucocorticoid-induced tumor necrosis factor receptor family-related protein (GITR) engagement completely abrogates Treg-mediated immunosuppression in 
HCC $^{[81]}$. These findings indicate that CLTA-4 is a promising target for HCC treatment. Recently, the CTLA-4 blockade agent, ipilimumab, has been tested in clinical trials of HCC treatment, with a partial response rate of $18 \%$ and a disease control rate of $76 \%{ }^{[82]}$. Duffy et al.'s ${ }^{[83]}$ study demonstrated that tremelimumab could achieve a partial response rate of $26 \%$ and a disease control rate of $84 \%$. Furthermore, the combination therapy of ipilimumab and nivolumab could achieve objective response rates of $31 \%$ and a median duration of 17.48 months in advanced HCC patients ${ }^{[84]}$. As with other cancers, the combination regimens of nivolumab and ipilimumab led to grade 3-4 treatment-related adverse events occurring in $37.7 \%$ patients, which were more frequently observed with combination regimens than with single-agents, especially in patients who received higher dosages of ipilimumab. However, most of the adverse events were manageable with timely recognition, steroid treatment, and discontinuation of immunotherapy, with a very low rate of liver failure ${ }^{[73,85,86]}$.

\section{Other immune checkpoint inhibitors}

The binding of inhibitory killer-immunoglobulin-like receptors (KIRs) expressed on NK cells with HLA class I molecules inhibit the activation of NK cells ${ }^{[87]}$. Antibodies against inhibitory KIRs enhance NK cell cytotoxicity. It was reported that KIR/HLA immunogenetic background influenced the evolution of $\mathrm{HCC}^{[88,89]}$. Anti-KIR antibodies - IPH2101 and IPH2102 - were well tolerated in patients with relapsed multiple myeloma ${ }^{[90,91]}$. However, little evidence emerged to confirm the efficacy of these anti-KIR antibodies against HCC. NKG2A is an inhibitor receptor expressed on both $\mathrm{CD} 8^{+} \mathrm{T}$ cells and NK cells ${ }^{[92,93]}$. Therefore, anti-NKG2A mAb promoted anticancer immunity of both $\mathrm{CD}^{+} \mathrm{T}$ and $\mathrm{NK}$ cells ${ }^{[94,95]}$. It has been shown that $\mathrm{NKG} 2 \mathrm{~A}$ mediated NK-cell exhaustion in patients with $\mathrm{HCC}^{[22]}$. However, the effect of anti-NKG2 A mAb on HCC needs to be confirmed in clinical trials. Increasing inhibitory receptors such as IL-1R8, TIM3, TIGIT, and CD96 have been found to be important for regulating NK cell activity against tumors ${ }^{[96-100]}$. Clinical trials have been performed to evaluate the efficiency of antibodies against these checkpoints for cancer therapy. The efficacy of NK cell-based checkpoint inhibitors in HCC needs further preclinical and clinical studies.

\section{Combination therapy with immune checkpoint inhibitors}

Immune checkpoint blockade leads to recovery of immune response against HCC cells and suppression of tumor growth in HCC. However, most HCC patients still do not achieve clinical benefit from ICI immunotherapy, highlighting the need for creative strategies to improve therapeutic efficacy. First, novel checkpoints need to be identified in HCC. For example, B and T cell lymphocyte attenuator has been found to participate in suppressing $\mathrm{CD}^{+} \mathrm{T}$ cell function in $\mathrm{HCC}^{[101]}$. Siglec-15 has been confirmed to be an immune suppressor and displays promising efficacy in cancer immunotherapy ${ }^{[102]}$. The roles of novel checkpoints in HCC have not been addressed. Second, novel combinations of checkpoints need to be designed. Zhou et al. ${ }^{[42]}$ found that T cells isolated from HCC tissue expressed high levels of PD-1, CTLA4, TIM3, and LAG3, suggesting the involvement of multiple checkpoints in T-cell exhaustion in HCC. The efficacy achieved by combining blockade of checkpoints was better than that by single checkpoint alone ${ }^{[42]}$. Therefore, a combination of ICIs might achieve better results than just monotherapy for HCC treatment. Moreover, the individualized combination for HCC patients can be designed based on omics-data to achieve precision medicine. Third, novel comprehensive combination needs to be tested. Wehrenberg-Klee et al. ${ }^{[103]}$ reported that combining radioembolization with nivolumab could enhance the ICI-induced anticancer immune response. Shigeta et al. ${ }^{[104]}$ found that dual anti-PD-1/VEGFR-2 therapy enhanced $\mathrm{CD}^{+}$cytotoxic $\mathrm{T}$ cell anticancer immune response in HCC. PD-1/PD-L1 double blockade increased anticancer immune response of vaccine-induced $\mathrm{CD} 8^{+} \mathrm{T}$ cells in advanced $\mathrm{HCC}$ patients ${ }^{[105]}$. To improve the benefits of ICI, it is necessary to integrate ICI therapy with targeted agents, locoregional therapy, vaccines, or other forms of therapy. Of note, the clinical outcomes of such integration require further investigation in future studies.

\section{Adoptive cell transfer}

NK cells and $\mathrm{CD}^{+} \mathrm{T}$ cells eliminate cancer cells by direct cytotoxicity. In advanced HCC, the scarcity of NK cells and $\mathrm{CD}^{+} \mathrm{T}$ cells in HCC tissues eliminates the ICI-induced anticancer efficacy. In this setting, it is absolutely necessary to adaptively transfer cytotoxic immune cells into patients with advanced HCC. 


\section{NK cell therapy}

NK cells have potent anticancer capacity. HLA class I molecule-independent activation endows NK cells with more potential for extensive applications. HLA class I molecules block the NK cell killing though interaction with KIRs or CD94/NKG2A/B on NK cells ${ }^{[106]}$. Meanwhile, stress-induced ligands on cancer cells can activate NK cells by interacting with activation receptors on them ${ }^{[107]}$. However, NK cell function is impaired and hardly restored in advanced cancers. Hence, adoptive transfer of NK cells is a valuable option for cancer therapy. However, adoptive transfer of autologous lymphokine-activated NK cells with IL-2 into patients with metastatic cancer led to a poor clinical outcome ${ }^{[108]}$, which might be attributed to high levels of HLA class I molecules on cancer cells and the exhausted function of patients' NK cells. To overcome these defects, allogeneic NK cells - especially allogeneic haploidentical NK cells - are harnessed to treat various malignancies ${ }^{[109]}$. Encouraging clinical efficacy has been observed in trials of acute myeloid leukemia ${ }^{[110]}$. Moreover, cryoablation combined with allogeneic NK cell therapy markedly improved the progression-free survival of patients with advanced $\mathrm{HCC}^{[111]}$. Besides autologous and allogeneic NK cells, NK-92 cells, an NK cell line, is also used in clinical trials of cancer therapy, with encouraging results observed in patients with advanced lung cancer ${ }^{[112]}$. To enhance the targetability of NK cells, Chimeric antigen receptor (CAR)NK cells have also been developed and pre-clinically evaluated. NK-92 cells with CD19-CAR display potent ability to kill $\mathrm{CD} 19^{+}$leukemia cell lines and lymphoblasts from patients with leukemia ${ }^{[113]}$. NK-92 cells with GPC3-CAR show significant in vitro cytotoxicity to $\mathrm{GPC}^{+}{ }^{+} \mathrm{HCC}$ cells and potent anticancer activity in HCC xenografts ${ }^{[114]}$. Accumulating evidence indicates that NK cell therapy is a potential approach for HCC treatment with technical improvements in the activation and expansion of NK cells.

\section{Cytokine-induced killer cell adjuvant therapy}

Cytokine-induced killer (CIK) cells generated from blood mononuclear cells cultured with IFN- $\gamma$, antiCD3, and IL-2 show potent anticancer activity ${ }^{[115]}$. Jia et al. ${ }^{[116]}$ reported that CIK cells improved overall survival in HCC. CIK cell adjuvant therapy also reduces the recurrence in HCC patients undergoing curative treatment ${ }^{[117]}$. Lee et al. ${ }^{[118]}$ found that the efficacy of CIK cells in patients with HCC lasted over 5 years. Chang et al. ${ }^{[119]}$ reported that the high number of $\mathrm{PD}-1^{+}$tumor infiltrating lymphocytes could predict the response and clinical benefits of CIK cell adjuvant immunotherapy in HCC patients. Pan et al. ${ }^{[120]}$ reported that CIK cell cytotoxicity is a predictive biomarker for adjuvant CIK cell immunotherapy of HCC patients after surgery. Collectively, increasing evidence suggests that CIK cell-based adjuvant immunotherapy shows modest efficacy in early-stage HCC. Although Wang et al. ${ }^{[121]}$ showed that intraperitoneal perfusion of CIK cells with local hyperthermia was safe for patients with advanced HCC, more clinical data on the efficacy of CIK cell therapy in advanced HCC is currently lacking. Further detailed studies on the characteristics of CIK cells and their recognition and effector function are required to improve the clinical outcomes of CIK cell adjuvant immunotherapy in HCC.

\section{CAR-redirected T cell therapy}

CAR-T cells have shown tremendous clinical efficacy in the therapy of hematological malignancies ${ }^{[122]}$. Moreover, CAR-T cell therapy is expected to convert cold tumors into hot tumors, which represents a promising immunotherapeutic option for HCC treatment. Glypican-3 (GPC3) is a membrane heparan sulfate and is highly expressed in HCC tissues ${ }^{[123,124]}$. Unfortunately, the GPC3-targeted antibody - GC33 was unsuccessful in bringing about clinical benefit to patients with HCC $^{[125]}$. However, the anti-GPC3/antiCD3 bispecific antibody - ERY974 - could activate T cells and convert the microenvironment of a cold tumor to that of a hot on ${ }^{[126]}$. Therefore, GPC3 is a promising target of CAR-T cells in HCC. Indeed, GPC3-CAR-T cells could eliminate GPC ${ }^{+} \mathrm{HCC}$ cells and tumors in a patient-derived xenograft model ${ }^{[127]}$. GPC3-CAR-T therapies have been registered for clinical trials. To overcome T-cell exhaustion induced by checkpoints, an enhanced version of CAR-T cells is being currently designed. For instance, PD-1 is disrupted via CRISPR/ Cas9 to enhance the activity of GPC3-CAR T cells against $\mathrm{HCC}^{[128]}$. A soluble PD-1-CH3 fusion protein is expressed to increase anticancer activities of GPC3-CAR-T cells ${ }^{[129]}$. Co-expressing GPC3-CAR and co- 
stimulatory molecule ICOSL-41BB promotes CAR-T cell proliferation and tumor rejection ${ }^{[130]}$. Besides GPC3, MUC-1, EpCAM, AFP, and CEA might be potential targets of CAR T cells for HCC treatment, which have been registered for clinical trials on the applicability of CAR-T therapy as a treatment strategy for $\mathrm{HCC}^{[131]}$. Moreover, these classical tumor-associated antigens and ligands for receptors expressed on T cells also act as the targets for HCC recognition. For instance, NKG2D-based CAR-T cells could potently eliminate $\mathrm{NKG}_{2} \mathrm{DL}^{+} \mathrm{HCC}$ cells ${ }^{[132]}$. A CD147-targeted inducible CAR-T cell system has been developed for HCC treatment ${ }^{[133]}$. Although clinical trials of CAR-T therapy against HCC have not been completed, CAR-T therapy might provide effective therapeutic modalities for HCC treatment. Nonetheless, to date, the therapeutic efficacy of CAR-T cells remains limited owing to the lack of cancer-specific targets, weak expansion, poor infiltration, and induced exhaustion of CAR-T cells. Hence, smarter optimization strategies and more clinical trials are required for the confirmation and improvement of clinical outcomes of CAR-T cells in HCC treatment.

\section{$T$ cell receptor-genetically engineered $T$ cell therapy}

The success of $\mathrm{T}$ cell receptor-genetically engineered $\mathrm{T}$ (TCR-T) cells in melanoma treatment has encouraged the use of TCR-T cells in HCC treatment. Autologous T cells forced to express an HBV-specific TCR recognized $\mathrm{HBsAg}^{+} \mathrm{HCC}$ cells and decreased HBsAg levels in a patient who underwent liver transplant ${ }^{[134]}$. T cells genetically engineered with HCV NS3:1406-1415-reactive TCR recognized the naturally processed antigen and led to suppression of $\mathrm{HCV}^{+} \mathrm{HCC}$ in vivo ${ }^{[135]}$. T cells genetically engineered with AFP-specific TCR specifically recognized and killed $\mathrm{AFP}^{+} \mathrm{HepG} 2$ cells, both in vitro and in vivo ${ }^{[136]}$. Although there remain many challenges such as off-target cross-reactivity and low TCR affinity that need to be overcome before successful translation into clinical practice ${ }^{[137,138]}$, increasing findings suggest that TCR-T therapy might be an attractive alternative immunotherapeutic modality for HCC treatment.

\section{DC-vaccines adjuvant immunotherapy}

Briefly, DCs are professional antigen-presenting cells with the capacity to prime antigen-specific T-cell immunity. DC vaccines are recognized as promising agents for activating $\mathrm{T}$ cells to eliminate cancer cells; their role and functions have been evaluated in some malignancies in clinical trials, including HCC. A phase II study using intravenous vaccination with DCs pulsed with HepG2 lysate was found to be safe and showed evidence of anticancer efficacy in some patients with advanced HCC ${ }^{[139]}$. Another phase I/II study reported that vaccination with DCs pulsed with AFP peptides induced strong T-cell immunity against AFP but no clinical responses in HCC patients ${ }^{[140]}$. Other phase I/IIa studies also reported that subcutaneous vaccination with DC pulsed with multiple antigens such as AFP, glypican-3 (GPC-3), and melanoma-associated antigen 1 (MAGE-1) enhanced anticancer immunity and prolonged time-to-recurrence and recurrence-free survival in HCC patients ${ }^{[141-143]}$. Interestingly, Lu et al. ${ }^{[144]}$ showed that exosomes derived from AFP-expressing DCs elicited potent anticancer immune responses and cancer regression in HCC mice, thus providing a novel option for vaccine-based immunotherapy of HCC. Pang et al ${ }^{[145]}$ reported that DCs fused with cancer stem cells could efficiently stimulate T lymphocytes to generate specific CD8 T cells against cancer stem cells. Collectively, several studies indicate that DC vaccine-based adjuvant therapy enhances anticancer immunity and improves the survival of patients with HCC. Nonetheless, further improvements such as specific immunogenic neoantigens for HCC, safe and feasible DC source, potent adjuvant, and access to vaccination are required for future success of DC-based HCC immunotherapy.

\section{Combination therapy of immune checkpoint blockade and adoptive cell transfer}

The existence of cancer immunosuppressive microenvironment limits the effector function of adoptive immune cells. Therefore, it is reasonable to improve the cancer immunosuppressive microenvironment to enhance the curative efficacy of adoptive immune cells on HCC. Kodumudi et al. ${ }^{[146]}$ reported that adoptive transfer of tumor infiltrating lymphocytes from tumors with anti-PD-L1 antibody treatment led to a significant delay in tumor growth, suggesting that pretreatment with immune checkpoint blockade could be 
an effective strategy to improve tumor infiltrating lymphocyte infiltration and function. Moreover, CAR-T cell therapy in combination with PD-1 blockade overcomes PD-L1-mediated cancer immunosuppression and leads to enhanced therapeutic efficacy ${ }^{[147]}$. The combination of CTLA-4 blockade with ACT also generates greater therapeutic efficacy ${ }^{[148]}$. Besides systemic delivery of checkpoint blockade, the knockout of immune checkpoint in CAR-T cells by gene-editing technologies improves anti-tumor efficacy of CAR-T cells in various cancer models by enhancing effector function and survival of T-cells ${ }^{[149]}$. It is understood that the immunosuppressive trait of the HCC microenvironment requires combinational therapeutic modalities for effective outcome ${ }^{[150]}$. These findings support combination immunotherapy with immune checkpoint blockade and ACT for cancers, which is expected to result in greater anticancer immune response than with either intervention alone.

\section{CONCLUSION}

Following significant therapeutic progress made on the basis of basic research, immunological studies offer a new era of clinical application. Immunotherapy brings a new hope to depressed patients with chronic infection, autoimmune disease, or cancers. More importantly, cytotoxic immune cell-based immunotherapy has markedly improved survival in patients with advanced cancers. The high mortality of patients with advanced HCC owing to resistance to chemotherapy highlights the importance and value of immunotherapy in HCC treatment, although the clinical efficiency has not been as promising as expected. The development of novel ICIs, cytokines, tumor-specific antigens, gene-modified/CAR NK cells, and TCR/CAR CD8 ${ }^{+} \mathrm{T}$ cells is expected to improve the curative effect. Furthermore, the flexible combination of immunotherapy and other therapies might offer the much required breakthrough in clinical efficacy of HCC treatment.

\section{DECLARATIONS}

\section{Authors' contributions}

Contributed to conception and design of the study and manuscript writing: Li J, Tao L, Wang X

Final approval of manuscripts: Li J, Tao L, Wang X

\section{Availability of data and materials}

Not applicable.

\section{Financial support and sponsorship}

This manuscript publication is funded by the Natural Science Foundation of China (\#31872741), Anhui Provincial Natural Science Foundation (grant numbers: 1708085QH183 and 1808085QC83), and Young Top Talent Program of Anhui Medical University, and Research Improvement Program of Anhui Medical University.

\section{Conflicts of interest}

All authors declared that there are no conflicts of interest.

\section{Ethical approval and consent to participate}

Not applicable.

\section{Consent for publication}

Not applicable

\section{Copyright}

(c) The Author(s) 2020. 


\section{REFERENCES}

1. Ferlay J, Soerjomataram I, Dikshit R, Eser S, Mathers C, et al. Cancer incidence and mortality worldwide: sources, methods and major patterns in GLOBOCAN 2012. Int J Cancer 2015;136:E359-86.

2. Gosalia AJ, Martin P, Jones PD. Advances and future directions in the treatment of hepatocellular carcinoma. Gastroenterol Hepatol (N Y) 2017;13:398-410.

3. Raoul JL, Kudo M, Finn RS, Edeline J, Reig M, et al. Systemic therapy for intermediate and advanced hepatocellular carcinoma: sorafenib and beyond. Cancer Treat Rev 2018;68:16-24.

4. Kudo M, Finn RS, Qin S, Han KH, Ikeda K, et al. Lenvatinib versus sorafenib in first-line treatment of patients with unresectable hepatocellular carcinoma: a randomised phase 3 non-inferiority trial. Lancet 2018;391:1163-73.

5. Bruix J, Qin S, Merle P, Granito A, Huang YH, et al. Regorafenib for patients with hepatocellular carcinoma who progressed on sorafenib treatment (RESORCE): a randomised, double-blind, placebo-controlled, phase 3 trial. Lancet 2017;389:56-66.

6. Finn RS, Merle P, Granito A, Huang YH, Bodoky G, et al. Outcomes of sequential treatment with sorafenib followed by regorafenib for HCC: additional analyses from the phase III RESORCE trial. J Hepatol 2018;69:353-8.

7. Abou-Alfa GK, Meyer T, Cheng AL, El-Khoueiry AB, Rimassa L, et al. Cabozantinib in patients with advanced and progressing hepatocellular carcinoma. N Engl J Med 2018;379:54-63.

8. Racanelli V, Rehermann B. The liver as an immunological organ. Hepatology 2006;43:S54-62.

9. Crispe IN. The liver as a lymphoid organ. Ann Rev Immunol 2009;27:147-63.

10. Heymann F, Tacke F. Immunology in the liver--from homeostasis to disease. Nat Rev Gastroenterol Hepatol 2016;13:88-110.

11. Kubes P, Jenne C. Immune Responses in the Liver. Ann Rev Immunol 2018;36:247-77.

12. Makarova-Rusher OV, Medina-Echeverz J, Duffy AG, Greten TF. The yin and yang of evasion and immune activation in HCC. J Hepatol 2015;62:1420-9.

13. Lu C, Rong D, Zhang B, Zheng W, Wang X, et al. Current perspectives on the immunosuppressive tumor microenvironment in hepatocellular carcinoma: challenges and opportunities. Mol Cancer 2019;18:130.

14. Cherrier DE, Serafini N, Di Santo JP. Innate lymphoid cell development: a T cell perspective. Immunity 2018;48:1091-103.

15. Peng H, Tian Z. Re-examining the origin and function of liver-resident NK cells. Trends Immunol 2015;36:293-9.

16. Chiossone L, Dumas PY, Vienne M, Vivier E. Natural killer cells and other innate lymphoid cells in cancer. Nat Rev Immunol 2018;18:671-88.

17. Martinet L, Smyth MJ. Balancing natural killer cell activation through paired receptors. Nat Rev Immunol 2015;15:243-54.

18. Pegram HJ, Andrews DM, Smyth MJ, Darcy PK, Kershaw MH. Activating and inhibitory receptors of natural killer cells. Immunol Cell Biol 2011;89:216-24.

19. Long EO, Kim HS, Liu D, Peterson ME, Rajagopalan S. Controlling natural killer cell responses: integration of signals for activation and inhibition. Ann Rev Immunol 2013;31:227-58.

20. Cai L, Zhang Z, Zhou L, Wang H, Fu J, et al. Functional impairment in circulating and intrahepatic NK cells and relative mechanism in hepatocellular carcinoma patients. Clin Immunol 2008;129:428-37.

21. Sun C, Sun H, Zhang C, Tian Z. NK cell receptor imbalance and NK cell dysfunction in HBV infection and hepatocellular carcinoma. Cell Mol Immunol 2015;12:292-302.

22. Sun C, Xu J, Huang Q, Huang M, Wen H, et al. High NKG2A expression contributes to NK cell exhaustion and predicts a poor prognosis of patients with liver cancer. Oncoimmunology 2017;6:e1264562.

23. Sun H, Huang Q, Huang M, Wen H, Lin R, et al. Human CD96 correlates to natural killer cell exhaustion and predicts the prognosis of human hepatocellular carcinoma. Hepatology 2019;70:168-83.

24. Zheng X, Qian Y, Fu B, Jiao D, Jiang Y, et al. Mitochondrial fragmentation limits NK cell-based tumor immunosurveillance. Nat Immunol 2019;20:1656-67.

25. Hoechst B, Voigtlaender T, Ormandy L, Gamrekelashvili J, Zhao F, et al. Myeloid derived suppressor cells inhibit natural killer cells in patients with hepatocellular carcinoma via the NKp30 receptor. Hepatology 2009;50:799-807.

26. Wu Y, Kuang DM, Pan WD, Wan YL, Lao XM, et al. Monocyte/macrophage-elicited natural killer cell dysfunction in hepatocellular carcinoma is mediated by CD48/2B4 interactions. Hepatology 2013;57:1107-16.

27. Li T, Yang Y, Hua X, Wang G, Liu W, et al. Hepatocellular carcinoma-associated fibroblasts trigger NK cell dysfunction via PGE2 and IDO. Cancer Lett 2012;318:154-61.

28. Tian Z, Chen Y, Gao B. Natural killer cells in liver disease. Hepatology 2013;57:1654-62.

29. Peng H, Jiang X, Chen Y, Sojka DK, Wei H, et al. Liver-resident NK cells confer adaptive immunity in skin-contact inflammation. J Clin Invest 2013;123:1444-56.

30. Nakano R, Ohira M, Yano T, Imaoka Y, Tanaka Y, et al. Hepatic irradiation persistently eliminates liver resident NK cells. PloS One 2018;13:e0198904.

31. Stegmann KA, Robertson F, Hansi N, Gill U, Pallant C, et al. CXCR6 marks a novel subset of T-bet(lo)Eomes(hi) natural killer cells residing in human liver. Sci Rep 2016;6:26157.

32. Bai L, Peng H, Hao X, Tang L, Sun C, et al. CD8 ${ }^{+} \mathrm{T}$ cells promote maturation of liver-resident NK cells through the CD70-CD27 axis. Hepatology 2019;70:1804-15.

33. Harmon C, Jameson G, Almuaili D, Houlihan DD, Hoti E, et al. Liver-derived TGF-beta maintains the Eomes(hi)Tbet(lo) phenotype of liver resident natural killer cells. Front Immunol 2019;10:1502.

34. Zhou J, Peng H, Li K, Qu K, Wang B, et al. Liver-resident NK cells control antiviral activity of hepatic T cells via the PD-1-PD-L1 axis. Immunity 2019;50:403-17.e4.

35. Zhao ZB, Lu FT, Ma HD, Wang YH, Yang W, et al. Liver-resident NK cells suppress autoimmune cholangitis and limit the 
proliferation of $\mathrm{CD}^{+}$T cells. Cell Mol Immunol 2019;17:178-89.

36. Hwang S, Han J, Baek JS, Tak E, Song GW, et al. Cytotoxicity of human hepatic intrasinusoidal CD56 ${ }^{\text {bright }}$ natural killer cells against hepatocellular carcinoma cells. Int J Mol Sci 2019;20:1564.

37. Easom NJW, Stegmann KA, Swadling L, Pallett LJ, Burton AR, et al. IL-15 overcomes hepatocellular carcinoma-induced NK cell dysfunction. Front Immunol 2018;9:1009.

38. Sun H, Liu L, Huang Q, Liu H, Huang M, et al. Accumulation of tumor-infiltrating CD49a ${ }^{+}$NK cells correlates with poor prognosis for human hepatocellular carcinoma. Cancer Immunol Res 2019;7:1535-46.

39. Saparbay J, Tanaka Y, Tanimine N, Ohira M, Ohdan H. Everolimus enhances TRAIL-mediated anti-tumor activity of liver resident natural killer cells in mice. Transpl Int 2020;33:229-43.

40. Gabrielson A, Wu Y, Wang H, Jiang J, Kallakury B, et al. Intratumoral CD3 and CD8 T-cell densities associated with relapse-free survival in HCC. Cancer Immunol Res 2016;4:419-30.

41. Kalathil SG, Hutson A, Barbi J, Iyer R, Thanavala Y. Augmentation of IFN-gamma+ CD8+ T cell responses correlates with survival of HCC patients on sorafenib therapy. JCI Insight 2019;4.

42. Zhou G, Sprengers D, Boor PPC, Doukas M, Schutz H, et al. Antibodies against immune checkpoint molecules restore functions of tumor-infiltrating T cells in hepatocellular carcinomas. Gastroenterology 2017;153:1107-19.e10.

43. Wang X, He Q, Shen H, Lu XJ, Sun B. Genetic and phenotypic difference in CD8 ${ }^{+} \mathrm{T}$ cell exhaustion between chronic hepatitis B infection and hepatocellular carcinoma. J Med Genet 2019;56:18-21.

44. Kim HD, Park S, Jeong S, Lee YJ, Lee H, et al. 4-1BB delineates distinct activation status of exhausted tumor-infiltrating CD $8^{+} \mathrm{T}$ cells in hepatocellular carcinoma. Hepatology 2020;71:955-71.

45. Miller BC, Sen DR, Al Abosy R, Bi K, Virkud YV, et al. Subsets of exhausted CD8 $8^{+} \mathrm{T}$ cells differentially mediate tumor control and respond to checkpoint blockade. Nat Immunol 2019;20:326-36.

46. Siddiqui I, Schaeuble K, Chennupati V, Fuertes Marraco SA, Calderon-Copete S, et al. Intratumoral Tcf1 $1^{+}$PD- $1^{+}$CD ${ }^{+}$T cells with stem-like properties promote tumor control in response to vaccination and checkpoint blockade immunotherapy. Immunity 2019;50:195211.e10.

47. Yang YM, Kim SY, Seki E. Inflammation and liver cancer: molecular mechanisms and therapeutic targets. Semin Liver Dis 2019;39:26-42.

48. Lim CJ, Lee YH, Pan L, Lai L, Chua C, et al. Multidimensional analyses reveal distinct immune microenvironment in hepatitis B virus-related hepatocellular carcinoma. Gut 2019;68:916-27.

49. Yarchoan M, Xing D, Luan L, Xu H, Sharma RB, et al. Characterization of the immune microenvironment in hepatocellular carcinoma. Clin Cancer Res 2017;23:7333-9.

50. Kalathil S, Lugade AA, Miller A, Iyer R, Thanavala Y. Higher frequencies of GARP ${ }^{+}$CTLA- $4^{+}$Foxp $3^{+}$T regulatory cells and myeloid-derived suppressor cells in hepatocellular carcinoma patients are associated with impaired T-cell functionality. Cancer Res 2013;73:2435-44

51. Yang L, Shao X, Jia S, Zhang Q, Jin Z. Interleukin-35 dampens CD8 ${ }^{+} \mathrm{T}$ cells activity in patients with non-viral hepatitis-related hepatocellular carcinoma. Front Immunol 2019;10:1032.

52. Huang XY, Ke AW, Shi GM, Zhang X, Zhang C, et al. alphaB-crystallin complexes with 14-3-3zeta to induce epithelial-mesenchymal transition and resistance to sorafenib in hepatocellular carcinoma. Hepatology 2013;57:2235-47.

53. Wang X, Shen H, Zhangyuan G, Huang R, Zhang W, et al. 14-3-3zeta delivered by hepatocellular carcinoma-derived exosomes impaired anti-tumor function of tumor-infiltrating T lymphocytes. Cell Death Dis 2018;9:159.

54. Aliahmad P, Seksenyan A, Kaye J. The many roles of TOX in the immune system. Curr Opin Immunol 2012;24:173-7.

55. Seo H, Chen J, González-Avalos E, Samaniego-Castruita D, Das A, et al. TOX and TOX2 transcription factors cooperate with NR4A transcription factors to impose CD8 ${ }^{+}$T cell exhaustion. Proc Natl Acad Sci U S A 2019;116:12410-5.

56. Scott AC, Dündar F, Zumbo P, Chandran SS, Klebanoff CA, et al. TOX is a critical regulator of tumour-specific T cell differentiation. Nature 2019;571:270-4

57. Wang X, He Q, Shen H, Xia A, Tian W, et al. TOX promotes the exhaustion of antitumor CD8 ${ }^{+} \mathrm{T}$ cells by preventing PD1 degradation in hepatocellular carcinoma. J Hepatol 2019;71:731-41.

58. Im SJ, Hashimoto M, Gerner MY, Lee J, Kissick HT, et al. Defining CD $8^{+}$T cells that provide the proliferative burst after PD-1 therapy. Nature 2016;537:417-21.

59. Gehring AJ, Ho ZZ, Tan AT, Aung MO, Lee KH, et al. Profile of tumor antigen-specific CD8 T cells in patients with hepatitis B virusrelated hepatocellular carcinoma. Gastroenterology 2009;137:682-90.

60. Hsu PN, Yang TC, Kao JT, Cheng KS, Lee YJ, et al. Increased PD-1 and decreased CD28 expression in chronic hepatitis B patients with advanced hepatocellular carcinoma. Liver Int 2010;30:1379-86.

61. Xiao X, Lao XM, Chen MM, Liu RX, Wei Y, et al. PD-1hi Identifies a novel regulatory B-cell population in human hepatoma that promotes disease progression. Cancer Discov 2016;6:546-59.

62. Lim TS, Chew V, Sieow JL, Goh S, Yeong JP, et al. PD-1 expression on dendritic cells suppresses CD8 ${ }^{+}$T cell function and antitumor immunity. Oncoimmunology 2016;5:e1085146.

63. Gao Q, Wang XY, Qiu SJ, Yamato I, Sho M, et al. Overexpression of PD-L1 significantly associates with tumor aggressiveness and postoperative recurrence in human hepatocellular carcinoma. Clin Cancer Res 2009;15:971-9.

64. Jung HI, Jeong D, Ji S, Ahn TS, Bae SH, et al. Overexpression of PD-L1 and PD-L2 is associated with poor prognosis in patients with hepatocellular carcinoma. Cancer Res Treat 2017;49:246-54.

65. Wu K, Kryczek I, Chen L, Zou W, Welling TH. Kupffer cell suppression of CD8 $8^{+} \mathrm{T}$ cells in human hepatocellular carcinoma is mediated by B7-H1/programmed death-1 interactions. Cancer Res 2009;69:8067-75.

66. Shi F, Shi M, Zeng Z, Qi RZ, Liu ZW, et al. PD-1 and PD-L1 upregulation promotes CD8(+) T-cell apoptosis and postoperative 
recurrence in hepatocellular carcinoma patients. Int J Cancer 2011;128:887-96.

67. Kuang DM, Xiao X, Zhao Q, Chen MM, Li XF, et al. B7-H1-expressing antigen-presenting cells mediate polarization of protumorigenic Th22 subsets. J Clin Invest 2014;124:4657-67.

68. Xia Y, Chen R, Ye SL, Sun R, Chen J, et al. Inhibition of T-cell responses by intratumoral hepatic stellate cells contribute to migration and invasion of hepatocellular carcinoma. Clin Exp Metastasis 2011;28:661-74.

69. He G, Zhang H, Zhou J, Wang B, Chen Y, et al. Peritumoural neutrophils negatively regulate adaptive immunity via the PD-L1/PD-1 signalling pathway in hepatocellular carcinoma. J Exp Clin Cancer Res 2015;34:141.

70. El-Khoueiry AB, Sangro B, Yau T, Crocenzi TS, Kudo M, et al. Nivolumab in patients with advanced hepatocellular carcinoma (CheckMate 040): an open-label, non-comparative, phase 1/2 dose escalation and expansion trial. Lancet 2017;389:2492-502.

71. Zhu AX, Finn RS, Edeline J, Cattan S, Ogasawara S, et al. Pembrolizumab in patients with advanced hepatocellular carcinoma previously treated with sorafenib (KEYNOTE-224): a non-randomised, open-label phase 2 trial. Lancet Oncol 2018;19:940-52.

72. Finn RS, Ryoo BY, Merle P, Kudo M, Bouattour M, et al. Pembrolizumab as second-line therapy in patients with advanced hepatocellular carcinoma in KEYNOTE-240: a randomized, double-blind, Phase III trial. J Clin Oncol 2020;38:193-202.

73. Cheng AL, Hsu C, Chan SL, Choo SP, Kudo M. Challenges of combination therapy with immune checkpoint inhibitors for hepatocellular carcinoma. J Hepatol 2020;72:307-19.

74. Floudas CS, Brar G, Greten TF. Immunotherapy: current status and future perspectives. Dig Dis Sci 2019;64:1030-40.

75. Reck M, Mok TSK, Nishio M, Jotte RM, Cappuzzo F, et al. Atezolizumab plus bevacizumab and chemotherapy in non-small-cell lung cancer (IMpower150): key subgroup analyses of patients with EGFR mutations or baseline liver metastases in a randomised, openlabel phase 3 trial. Lancet Respir Med 2019;7:387-401.

76. Chau I, Peck-Radosavljevic M, Borg C, Malfertheiner P, Seitz JF, et al. Ramucirumab as second-line treatment in patients with advanced hepatocellular carcinoma following first-line therapy with sorafenib: patient-focused outcome results from the randomised phase III REACH study. Eur J Cancer 2017;81:17-25.

77. Krummel MF, Allison JP. CD28 and CTLA-4 have opposing effects on the response of T cells to stimulation. J Exp Med 1995; 182:459-65.

78. Liu Z, Song Z, Sun J, Sun F, Li C, et al. Association between CTLA-4 rs231775 polymorphism and hepatocellular carcinoma susceptibility. Int J Clin Exp Pathol 2015;8:15118-22.

79. Chen X, Du Y, Hu Q, Huang Z. Tumor-derived $\mathrm{CD} 4{ }^{+} \mathrm{CD} 25^{+}$regulatory T cells inhibit dendritic cells function by CTLA-4. Pathol Res Pract 2017;213:245-9.

80. Han Y, Chen Z, Yang Y, Jiang Z, Gu Y, et al. Human CD14 CTLA-4 $4^{+}$regulatory dendritic cells suppress T-cell response by cytotoxic T-lymphocyte antigen-4-dependent IL-10 and indoleamine-2,3-dioxygenase production in hepatocellular carcinoma. Hepatology 2014;59:567-79.

81. Pedroza-Gonzalez A, Zhou G, Singh SP, Boor PP, Pan Q, et al. GITR engagement in combination with CTLA-4 blockade completely abrogates immunosuppression mediated by human liver tumor-derived regulatory T cells ex vivo. Oncoimmunology 2015;4:e1051297.

82. Sangro B, Gomez-Martin C, de la Mata M, Iñarrairaegui M, Garralda E, et al. A clinical trial of CTLA-4 blockade with tremelimumab in patients with hepatocellular carcinoma and chronic hepatitis C. J Hepatol 2013;59:81-8.

83. Duffy AG, Ulahannan SV, Makorova-Rusher O, Rahma O, Wedemeyer H, et al. Tremelimumab in combination with ablation in patients with advanced hepatocellular carcinoma. J Hepatol 2017;66:545-51.

84. Yau T, Kang YK, Kim TY, El-Khoueiry AB, Santoro A, et al. Nivolumab (NIVO) + ipilimumab (IPI) combination therapy in patients (pts) with advanced hepatocellular carcinoma (aHCC): results from CheckMate 040. J Clin Oncol 2019;37:4012.

85. Kaseb A, Vence L, Blando J, Yadav S, Ikoma N, et al. Randomized, open-label, perioperative phase II study evaluating nivolumab alone versus nivolumab plus ipilimumab in patients with resectable HCC. Ann Oncol 2019;30:iv112.

86. Hellmann MD, Paz-Ares L, Bernabe Caro R, Zurawski B, Kim SW, et al. Nivolumab plus ipilimumab in advanced non-small-cell lung cancer. N Engl J Med 2019;381:2020-31.

87. Purdy AK, Campbell KS. Natural killer cells and cancer: regulation by the killer cell Ig-like receptors (KIR). Cancer Biol Ther 2009;8:2211-20

88. Cariani E, Missale G. KIR/HLA immunogenetic background influences the evolution of hepatocellular carcinoma. Oncoimmunology 2013;2:e26622.

89. Pan N, Qiu J, Sun H, Miao F, Shi Q, et al. Combination of human leukocyte antigen and killer cell immunoglobulin-like receptor genetic background influences the onset age of hepatocellular carcinoma in male patients with hepatitis B virus infection. Clin Dev Immunol 2013;2013:874514.

90. Vey N, Karlin L, Sadot-Lebouvier S, Broussais F, Berton-Rigaud D, et al. A phase 1 study of lirilumab (antibody against killer immunoglobulin-like receptor antibody KIR2D; IPH2102) in patients with solid tumors and hematologic malignancies. Oncotarget 2018;9:17675-88.

91. Benson DM Jr, Hofmeister CC, Padmanabhan S, Suvannasankha A, Jagannath S, et al. A phase 1 trial of the anti-KIR antibody IPH2 101 in patients with relapsed/refractory multiple myeloma. Blood 2012;120:4324-33.

92. van Montfoort N, Borst L, Korrer MJ, Sluijter M, Marijt KA, et al. NKG2A blockade potentiates CD8 T cell immunity induced by cancer vaccines. Cell 2018;175:1744-55.e15.

93. Xu HC, Huang J, Pandyra AA, Lang E, Zhuang Y, et al. Lymphocytes negatively regulate NK cell activity via Qa-1b following viral infection. Cell Rep 2017;21:2528-40.

94. André P, Denis C, Soulas C, Bourbon-Caillet C, Lopez J, et al. Anti-NKG2A mAb is a checkpoint inhibitor that promotes anti-tumor immunity by unleashing both $\mathrm{T}$ and NK cells. Cell 2018;175:1731-43.e13.

95. Kamiya T, Seow SV, Wong D, Robinson M, Campana D. Blocking expression of inhibitory receptor NKG2A overcomes tumor resistance to NK cells. J Clin Invest 2019;129:2094-106. 
96. Zhang Q, Bi J, Zheng X, Chen Y, Wang H, et al. Blockade of the checkpoint receptor TIGIT prevents NK cell exhaustion and elicits potent anti-tumor immunity. Nat Immunol 2018;19:723-32.

97. Stanietsky N, Simic H, Arapovic J, Toporik A, Levy O, et al. The interaction of TIGIT with PVR and PVRL2 inhibits human NK cell cytotoxicity. Proc Natl Acad Sci U S A 2009;106:17858-63.

98. Molgora M, Bonavita E, Ponzetta A, Riva F, Barbagallo M, et al. IL-1R8 is a checkpoint in NK cells regulating anti-tumour and antiviral activity. Nature 2017;551:110-4.

99. Ndhlovu LC, Lopez-Vergès S, Barbour JD, Jones RB, Jha AR, et al. Tim-3 marks human natural killer cell maturation and suppresses cell-mediated cytotoxicity. Blood 2012;119:3734-43.

100. Chan CJ, Martinet L, Gilfillan S, Souza-Fonseca-Guimaraes F, Chow MT, et al. The receptors CD96 and CD226 oppose each other in the regulation of natural killer cell functions. Nat Immunol 2014;15:431-8.

101. Zhao Q, Huang ZL, He M, Gao Z, Kuang DM. BTLA identifies dysfunctional PD-1-expressing CD4 ${ }^{+} \mathrm{T}$ cells in human hepatocellular carcinoma. Oncoimmunology 2016;5:e1254855.

102. Wang J, Sun J, Liu LN, Flies DB, Nie X, et al. Siglec-15 as an immune suppressor and potential target for normalization cancer immunotherapy. Nat Med 2019;25:656-66.

103. Wehrenberg-Klee E, Goyal L, Dugan M, Zhu AX, Ganguli S. Y-90 radioembolization combined with a PD-1 inhibitor for advanced hepatocellular carcinoma. Cardiovasc Intervent Radiol 2018;41:1799-802.

104. Shigeta K, Datta M, Hato T, Kitahara S, Chen IX, et al. Dual programmed death receptor-1 and vascular endothelial growth factor receptor-2 blockade promotes vascular normalization and enhances antitumor immune responses in hepatocellular carcinoma. Hepatology 2019.

105. Sawada Y, Yoshikawa T, Shimomura M, Iwama T, Endo I, et al. Programmed death-1 blockade enhances the antitumor effects of peptide vaccine-induced peptide-specific cytotoxic T lymphocytes. Int J Oncol 2015;46:28-36.

106. Ljunggren HG, Kärre K. In search of the 'missing self': MHC molecules and NK cell recognition. Immunol Today 1990;11:237-44.

107. Shifrin N, Raulet DH, Ardolino M. NK cell self tolerance, responsiveness and missing self recognition. Semin Immunol 2014;26:138-44.

108. Rosenberg SA, Lotze MT, Muul LM, Leitman S, Chang AE, et al. Observations on the systemic administration of autologous lymphokine-activated killer cells and recombinant interleukin-2 to patients with metastatic cancer. N Engl J Med 1985;313:1485-92.

109. Miller JS, Soignier Y, Panoskaltsis-Mortari A, McNearney SA, Yun GH, et al. Successful adoptive transfer and in vivo expansion of human haploidentical NK cells in patients with cancer. Blood 2005;105:3051-7.

110. Romee R, Rosario M, Berrien-Elliott MM, Wagner JA, Jewell BA, et al. Cytokine-induced memory-like natural killer cells exhibit enhanced responses against myeloid leukemia. Sci Transl Med 2016;8:357ra123.

111. Lin M, Liang S, Wang X, Liang Y, Zhang M, et al. Cryoablation combined with allogenic natural killer cell immunotherapy improves the curative effect in patients with advanced hepatocellular cancer. Oncotarget 2017;8:81967-77.

112. Tonn T, Schwabe D, Klingemann HG, Becker S, Esser R, et al. Treatment of patients with advanced cancer with the natural killer cell line NK-92. Cytotherapy 2013;15:1563-70.

113. Romanski A, Uherek C, Bug G, Seifried E, Klingemann H, et al. CD19-CAR engineered NK-92 cells are sufficient to overcome NK cell resistance in B-cell malignancies. J Cell Mol Med 2016;20:1287-94.

114. Yu M, Luo H, Fan M, Wu X, Shi B, et al. Development of GPC3-specific chimeric antigen receptor-engineered natural killer cells for the treatment of hepatocellular carcinoma. Mol Ther 2018;26:366-78.

115. Xiao Z, Wang CQ, Feng JH, Zhou MH, Wang YZ, et al. Effectiveness and safety of chemotherapy with cytokine-induced killer cells in non-small cell lung cancer: a systematic review and meta-analysis of 32 randomized controlled trials. Cytotherapy 2019;21:125-47.

116. Jia CC, Chen YH, Cai XR, Li Y, Zheng XF, et al. Efficacy of cytokine-induced killer cell-based immunotherapy for hepatocellular carcinoma. Am J Cancer Res 2019;9:1254-65.

117. Lee JH, Lee JH, Lim YS, Yeon JE, Song TJ, et al. Adjuvant immunotherapy with autologous cytokine-induced killer cells for hepatocellular carcinoma. Gastroenterology 2015;148:1383-91.e6.

118. Lee JH, Lee JH, Lim YS, Yeon JE, Song TJ, et al. Sustained efficacy of adjuvant immunotherapy with cytokine-induced killer cells for hepatocellular carcinoma: an extended 5-year follow-up. Cancer Immunol Immunother 2019;68:23-32.

119. Chang B, Shen L, Wang K, Jin J, Huang T, et al. High number of PD-1 positive intratumoural lymphocytes predicts survival benefit of cytokine-induced killer cells for hepatocellular carcinoma patients. Liver Int 2018;38:1449-58.

120. Pan QZ, Liu Q, Zhou YQ, Zhao JJ, Wang QJ, et al. CIK cell cytotoxicity is a predictive biomarker for CIK cell immunotherapy in postoperative patients with hepatocellular carcinoma. Cancer Immunol Immunother 2020; Epub ahead of print. doi:10.1007/s00262020-02486-y

121. Wang XP, Xu M, Gao HF, Zhao JF, Xu KC. Intraperitoneal perfusion of cytokine-induced killer cells with local hyperthermia for advanced hepatocellular carcinoma. World J Gastroenterol 2013;19:2956-62.

122. Liu Y, Chen X, Han W, Zhang Y. Tisagenlecleucel, an approved anti-CD19 chimeric antigen receptor T-cell therapy for the treatment of leukemia. Drugs Today (Barc) 2017;53:597-608.

123. Zhu ZW, Friess H, Wang L, Abou-Shady M, Zimmermann A, et al. Enhanced glypican-3 expression differentiates the majority of hepatocellular carcinomas from benign hepatic disorders. Gut 2001;48:558-64.

124. Filmus J, Capurro M. Glypican-3: a marker and a therapeutic target in hepatocellular carcinoma. FEBS J 2013;280:2471-6.

125. Abou-Alfa GK, Puig O, Daniele B, Kudo M, Merle P, et al. Randomized phase II placebo controlled study of codrituzumab in previously treated patients with advanced hepatocellular carcinoma. J Hepatol 2016;65:289-95.

126. Ishiguro T, Sano Y, Komatsu SI, Kamata-Sakurai M, Kaneko A, et al. An anti-glypican 3/CD3 bispecific T cell-redirecting antibody for treatment of solid tumors. Sci Transl Med 2017;9:eaal4291.

127. Gao H, Li K, Tu H, Pan X, Jiang H, et al. Development of T cells redirected to glypican-3 for the treatment of hepatocellular carcinoma. Clin Cancer Res 2014;20:6418-28. 
128. Guo X, Jiang H, Shi B, Zhou M, Zhang H, et al. Disruption of PD-1 enhanced the anti-tumor activity of chimeric antigen receptor T cells against hepatocellular carcinoma. Front Pharmacol 2018;9:1118.

129. Pan Z, Di S, Shi B, Jiang H, Shi Z, et al. Increased antitumor activities of glypican-3-specific chimeric antigen receptor-modified T cells by coexpression of a soluble PD1-CH3 fusion protein. Cancer Immunol Immunother 2018;67:1621-34.

130. Hu W, Huang X, Huang X, Chen W, Hao L, et al. Chimeric antigen receptor modified T cell (CAR-T) co-expressed with ICOSL-41BB promote CAR-T proliferation and tumor rejection. Biomed Pharmacother 2019;118:109333.

131. Chen Y, E CY, Gong ZW, Liu S, Wang ZX, et al. Chimeric antigen receptor-engineered T-cell therapy for liver cancer. Hepatobiliary Pancreat Dis Int 2018;17:301-9.

132. Sun B, Yang D, Dai H, Liu X, Jia R, et al. Eradication of hepatocellular carcinoma by NKG2D-based CAR-T cells. Cancer Immunol Res 2019;7:1813-23.

133. Zhang RY, Wei D, Liu ZK, Yong YL, Wei W, et al. Doxycycline inducible chimeric antigen receptor T cells targeting CD147 for hepatocellular carcinoma therapy. Front Cell Dev Biol 2019;7:233.

134. Qasim W, Brunetto M, Gehring AJ, Xue SA, Schurich A, et al. Immunotherapy of HCC metastases with autologous T cell receptor redirected T cells, targeting HBsAg in a liver transplant patient. J Hepatol 2015;62:486-91.

135. Spear TT, Callender GG, Roszkowski JJ, Moxley KM, Simms PE, et al. TCR gene-modified T cells can efficiently treat established hepatitis C-associated hepatocellular carcinoma tumors. Cancer Immunol Immunother 2016;65:293-304.

136. Zhu W, Peng Y, Wang L, Hong Y, Jiang X, et al. Identification of alpha-fetoprotein-specific T-cell receptors for hepatocellular carcinoma immunotherapy. Hepatology 2018;68:574-89.

137. Spear TT, Evavold BD, Baker BM, Nishimura MI. Understanding TCR affinity, antigen specificity, and cross-reactivity to improve TCR gene-modified T cells for cancer immunotherapy. Cancer Immunol Immunother 2019;68:1881-9.

138. Tendeiro Rego R, Morris EC, Lowdell MW. T-cell receptor gene-modified cells: past promises, present methodologies and future challenges. Cytotherapy 2019;21:341-57.

139. Palmer DH, Midgley RS, Mirza N, Torr EE, Ahmed F, et al. A phase II study of adoptive immunotherapy using dendritic cells pulsed with tumor lysate in patients with hepatocellular carcinoma. Hepatology 2009;49:124-32.

140. Butterfield LH, Ribas A, Dissette VB, Lee Y, Yang JQ, et al. A phase I/II trial testing immunization of hepatocellular carcinoma patients with dendritic cells pulsed with four alpha-fetoprotein peptides. Clin Cancer Res 2006;12:2817-25.

141. Tada F, Abe M, Hirooka M, Ikeda Y, Hiasa Y, et al. Phase I/II study of immunotherapy using tumor antigen-pulsed dendritic cells in patients with hepatocellular carcinoma. Int J Oncol 2012;41:1601-9.

142. Lee JH, Lee Y, Lee M, Heo MK, Song JS, et al. A phase I/IIa study of adjuvant immunotherapy with tumour antigen-pulsed dendritic cells in patients with hepatocellular carcinoma. Br J Cancer 2015;113:1666-76.

143. Lee JH, Tak WY, Lee Y, Heo MK, Song JS, et al. Adjuvant immunotherapy with autologous dendritic cells for hepatocellular carcinoma, randomized phase II study. Oncoimmunology 2017;6:e1328335.

144. Lu Z, Zuo B, Jing R, Gao X, Rao Q, et al. Dendritic cell-derived exosomes elicit tumor regression in autochthonous hepatocellular carcinoma mouse models. J Hepatol 2017;67:739-48.

145. Pang YB, He J, Cui BY, Xu S, Li XL, et al. A potential antitumor effect of dendritic cells fused with cancer stem cells in hepatocellular carcinoma. Stem Cells Int 2019;2019:5680327.

146. Kodumudi KN, Siegel J, Weber AM, Scott E, Sarnaik AA, et al. Immune checkpoint blockade to improve tumor infiltrating lymphocytes for adoptive cell therapy. PloS One 2016;11:e0153053.

147. John LB, Devaud C, Duong CP, Yong CS, Beavis PA, et al. Anti-PD-1 antibody therapy potently enhances the eradication of established tumors by gene-modified T cells. Clin Cancer Res 2013;19:5636-46.

148. Mahvi DA, Meyers JV, Tatar AJ, Contreras A, Suresh M, et al. Ctla-4 blockade plus adoptive T-cell transfer promotes optimal melanoma immunity in mice. J Immunother 2015;38:54-61.

149. Jung IY, Lee J. Unleashing the therapeutic potential of CAR-T cell therapy using gene-editing technologies. Mol Cells 2018;41:717-23.

150. Zhang R, Zhang Z, Liu Z, Wei D, Wu X, et al. Adoptive cell transfer therapy for hepatocellular carcinoma. Front Med 2019;13:3-11. 